\title{
Native Speakers' Perception of Non - Native English Speech
}

\author{
Maysa Jaber \\ Middle East University, P. O. Box 42, Amman 11610, Jordan
}

Tel: 96-2799-999-333 E-mail: mais_jaber@hotmail.com

Riyad F. Hussein

Middle East University, P. O. Box 42, Amman 11610, Jordan

Tel: 96-2796-703-868Ｅ-mail: rfhussein@hotmail.com

Received: August 22, 2011

Accepted: September 13, $2011 \quad$ Published: December 1, 2011

doi:10.5539/elt.v4n4p77

URL: http://dx.doi.org/10.5539/elt.v4n4p77

\begin{abstract}
This study is aimed at investigating the rating and intelligibility of different non-native varieties of English, namely French English, Japanese English and Jordanian English by native English speakers and their attitudes towards these foreign accents. To achieve the goals of this study, the researchers used a web-based questionnaire which targeted native speakers of English. The materials for this study were a questionnaire for respondents to fill out and tape recordings of six different short stories, each of which was recorded by a non native speaker of English. The first short story was tape- recorded by a male French speaker and the second by a female French speaker. Similarly, the other four short stories were tape-recorded by male and female Japanese and Jordanian speakers respectively. The respondents or raters consisted of 110 native speakers of English (78 females and 32 females); the majority of them from the USA, but there were others from Britain, Canada, and Australia. They were requested to surf the webpage www. englishforeignaccent .com, especially designed by the researchers, fill out the questionnaire and rate the non-native varieties under investigation, and four months later the number of respondents reached one hundred and ten which constituted the sample of the study.

Data obtained indicated that the Jordanian accent was considered as the most intelligible, followed by the French then the Japanese English accent. The native speakers also showed significantly more positive attitudes towards Jordanian English than French and Japanese English. Finally, the positive attitude towards Jordanian English was affirmed by the respondents who assigned the Jordanian English speakers to the most prestigious professions such as medicine and teaching.
\end{abstract}

Keywords: Language perception, Stereotypes, Foreign accent, Language intelligibility, Native speech, Language attitudes

\section{Introduction}

English has become a universal language. It is the official language of the United Nations, NATO, sports, cinema, aviation, marine communications, radio and television programs and the internet. This spread of English makes it an international language where native and non-native speakers use it to communicate. It is not surprising that the number of English speakers as a second/ foreign language is greater than the number of native English speakers.

It is increasingly clear that English belongs to all who use it although it is not spoken the same way everywhere. The wide use of English has led to the notion of world Englishes, which presents English as a set of distinctive varieties, rather than one linguistic entity. These varieties can be divided into two parts: English for native speakers which is used in the United States, the United Kingdom, Australia, Canada and New Zealand, and English for non- native speakers which is used in countries such as Japan, France, India, Nigeria and Jordan.

The widespread use of English generates a large number of linguistic issues, questions and problems which require investigations and solutions. One of these problems is the increasing number of different English foreign accents, their differences, intelligibility and the native speakers' attitude towards accented foreign speech.

There are many reasons behind these differences such as the age of English learners, the length of residence and the phonological system of the mother language. Flege, Birdsong, Bialystok, Mack, Sung \& Tsukada, (1988) accordingly, stated that when speakers have different utterances, listeners will have different intelligibility. 
Utterances in English might be fully or partially understood by native or non- native English listeners since listeners are sometimes unable to recognize phonetic segments when pronounced with different accent.

\subsection{Background of the study}

Since the investigation of accents ranges over a multitude of different disciplines of interest, we have more than one definition from different core areas of linguistics. This section provides an illustration of how the concept of foreign accent has been defined in different areas of research, and in some core areas of linguistics such as phonetics, sociolinguistics, psycholinguistics, second language acquisition and foreign language teaching.

In order to define the word accent, some researchers differentiated between dialect and accent; Gill identified the distinction between accents and dialects as follows:

"Although dialects and accents are often used as synonyms, the former traditionally refers to regional variations in language and the latter refers to differences among national groups. For example, the differences in sound between a Bostonian and Iowan would be a matter of dialect while the differences between a New Zealander and an American would be a matter of accent." (1994: 348). Thomas (1999) also distinguished between accent and dialect; for her, accent refers to pronunciation; she considered speaking in a regional accent as pronouncing the words in a manner associated with a certain geographical area, whereas dialect refers to grammar and vocabulary.

Munro defined foreign-accented speech as "non-pathological speech produced by second language learners that differs in partially systematic ways from the speech characteristics of native speakers of a given dialect." (1998: 139) In addition, Flege, Munro \& Mackay identified foreign accent in English from the listener's perspective: "listeners hear foreign accents when they detect divergences from English phonetic norms along wide range of segmental and supra-segmental i.e. prosodic dimensions" (1995: 233).

From phoneticians' point of view, Scovel stated that "accent refers to the deviations in pronunciation of non-native speech compared to the norms of native speech". (1969: 38) Flege (1984) studied foreign accent from different perspectives and stated that it can be detected through the acoustic differences between native and non-native speakers' segmental articulations, suprasegmental and sub segmental levels. He also included voice onset times (VOT) which differs between non native and native speakers of English. Flege (1995) identified foreign accent from listener's perspective: "listeners hear foreign accents when they detect divergences from English phonetic norms along a wide range of segmental and non-native suprasegmental dimensions."(p. 233)

Arslan \& Hansen (1996) maintained that an accent, which is considered as a model of pronunciation features, can characterize an individual's speech as belonging to a particular language group. They also considered that each individual, depending on his language environment, develops a characteristic speaking style.

César Lee considered the accent process as defective in different manners: "faulty production of a target language or L2 due to faulty perception, faulty articulation or a combination of both" (1999.1). Finally, Felps, Bortfeld \& Osuna (2009) stated that foreign accent can be a deviation from the expected acoustic and prosodic norms of language.

Other important theoretical concepts concerning the study of foreign accent include the intelligibility and comprehensibility of non-native utterances. In this field, Derwing and Munro and through their different studies (1995a, 1995b, 2003) mentioned that these concepts are linked but with partially independent relationship: Derwing distinguished between these three dimensions (2003: 554) as:

Accentedness: the degree to which the listener believes an utterance differs phonetically from native speaker utterances.

Comprehensibility: the degree of difficulty the listener reports in attempting to understand the utterance.

Intelligibility: the extent to which a particular utterance is actually understood.

Foreign accents are often associated with low intelligibility and negative personal evaluations of nonnative speakers (Flege 1984). Intelligibility refers to the word recognition whereas comprehensibility refers to the word meaning measured by listeners' perceptions for how much they could understand. These two dimensions will be the focus of the present study.

Khalil (1996) analyzed the sound system of Arabic and English. He stated that there are some English consonants which did not have counterparts in Arabic such as /p/, /v/, /g/ and the flap /r/. In addition, English has twelve vowels while Arabic has a triangle vowel system that consists of three pairs of short and long vowels. Hence, some English vowels do not have counterparts in Arabic. Therefore, Arab learners of English as a second language will experience some difficulties in producing these consonants (for example, to say pat they might pronounce /bat/ instead of /pat/. They are also expected to make erroneous substitution for some vowels. "For example, they will tend to produce sit and set." (1996: 22). 
Khalil also explained that Arab speakers of English would face some difficulties in producing words which contain clusters especially the initial clusters because English has longer sequences of clusters. For example, they are expected to break initial clusters by inserting a vowel before or between the vowels that make up the cluster; they are expected to pronounce spring as /aspring/ or /sapring/.

Sociolinguistics considers accent as a means to show different people belonging to a particular speech community and also as a means of defining them. In effect, Munro \& Derwing (1995a) considered the accent as a symbol of social identity. Becker reported that the accent could identify a person more than anything else "An accent is the part of a person's language that serves to identify the speaker's regional origin or national/ethnic identity no matter what language the person is speaking" (1995: 37).

Moreover, sociolinguists investigated the negative attitudes towards accented speech which causes prejudice and discrimination. Discrimination and accent first start with children; they are taught to characterize the accent in a negative way through watching animated films in which racial stereotyping is he language acquisition: the age of learning, length of residence, non native ability to gauge a foreign accent, gender, formal instruction and the amount of L1 or L2 use. Suter (1976) added another variable which was the phonological system of the speaker's mother tongue. Despite the importance of other variables such as gender, age and education in the study of accented speech, they have not been investigated because they are not within the scope of this article and are thus recommended for further research.

\section{Research Methods}

\subsection{Participants}

The participants in the study consisted of two groups (the speakers and the listeners). The first group consisted of six different non-native English speakers with foreign accented English of the three accents under investigation namely French, Japanese and Jordanian English, who were equally distributed by the gender variable. The speakers were enrolled in the English department or in other departments where English was the language of instruction. Their English proficiency level was considerably advanced and they were taught English at school by non native English teachers.

The second group was the participants or subjects who evaluated the speech of the first group. They were one hundred and ten native speakers of English (78 females and 32 males). They were asked to rate the different English group accents. The majority of the raters 80 or $72.7 \%$ were from the US, 13 or $11.8 \%$ from Britain, 12 or $10.9 \%$ from Canada and 5 or $4.5 \%$ from Australia.

\subsection{Instrument of the study}

The instrument of the study was a three section questionnaire which was designed particularly for this study and posted on the internet (www. englishforeignaccent. com) for native English volunteers to fill out. The first section elicited personal and biographical data such as age, sex, nationality and level of education.

The second section elicited data on subjects' attitudes towards English accented speech and consisted of 12 items. The subjects were asked to rate the speech of non native English speakers using a five-point Likert type scale with bipoloar adjectives, by circling the number which is closest to the adjective reflecting their opinion ( educated vs. uneducated, pleasant, unpleasant, and each was measured on a scale of one to five as in the following example.

Unpleasant ........1 .........2..................................Pleasant.

The higher the number, the more positive attitude and perception of non native accent.

In addition, there were two questions for respondents or raters to guess the speakers' profession and nationality. The third section elicited data on subjects understanding and comprehension of the recorded texts, and consisted of seven questions. In the first four questions subjects were again asked to rate the speech of non native speakers using a five-point Likert type scale by circling the number which is closest to the adjective reflecting their opinion. In the last three questions of this section subjects were asked to judge speakers' fluency, pronunciation, accuracy and intonation patterns. (See Appendix 1)

\subsection{Materials}

The researchers used six different short stories, each of which was read by one of the six subjects. The stories were funny and interesting, using English common words with appropriate length. They were titled The Coffin, Vinder Viper, The Mosquitoes, Jobs at the Zoo, Origin of Fire and finally The Princess and the Pea (See Appendix 2) They were different to ensure that the listeners would evaluate each spoken text individually, because if the same story was used, the listeners would understand the speech of the second speaker more than the first due to earlier exposure to it. 


\subsection{Procedures}

The short stories were distributed to the speakers randomly. They were tape-recorded separately and listeners were given the chance to read the stories immediately before tape- recording them. They were also given the opportunity to practice reading the passage prior to actual recording. This precaution was taken to guarantee a relaxed, clear and uninterrupted delivery of the reading.

Immediately before tape- recording of the short stories, each speaker was given a story text to read silently first and then to ask about the pronunciation of any unfamiliar words and finally to tape record it. This was done to eliminate the possibility of committing pronunciation errors because of unfamiliarity with words or orthographic cues.

\section{Data Analysis}

Data were collected by means of a web based survey questionnaire covering the aspects of the study (www.englishforeignaccent.com) The raw data drawn from the questionnaire, were recorded, analyzed, and interpreted in tables each of which was followed by simple descriptive and statistical procedures (i.e. percentages and means)

For the purpose of scoring consistency, the unfavorable poles of the evaluative scales (e.g. unpleasant, uneducated) were uniformly assigned the score "1" and the score "5" for the favorable poles, ( e.g. pleasant, educated). Scoring simply required summing over all evaluative ratings to obtain the attitude score of the French, Japanese and Jordanian speakers' accents. In addition, means were calculated for all the items by adding the response values and dividing them by the number of subjects or respondents

\subsection{Respondents' attitudes}

In order to measure the attitudes towards French, Japanese and Jordanian English accents, respondents were instructed to choose a number on a five-point scale presenting the adjectives which they found closest or more related to the speaker accent, the higher the number, the more positive the attitude to accented speech and the lower the number, the less positive the attitude towards a given accented speech.

\section{Insert Table 1 here}

Results in Table 1 related to native speakers' attitudes towards French Japanese and Jordanian English accented speech showed that the French speakers (male and female) were rated more positively than the Japanese speakers, but less positively than the Jordanian speakers. French speakers' level of education, smartness, attractiveness, wealth, had got significantly more positive rating than that of the Japanese speakers but less positive rating than the Jordanian speakers. The mean scores of the education trait were 3.6 for the French 2.8 for the Japanese speakers and 4.1 for the Jordanians. In addition, the mean scores of the trait of smartness were 3.55 for the French and 3.0 for the Japanese and 4.25 for the Jordanian speakers and the mean scores of the attractiveness trait were 3.25 for the French, 2.65 for the Japanese and 3.75 for the Jordanian speakers. Finally, the overall mean scores of all the traits were 2.85 for the Japanese, 3.39 for the French and 4.07 for the Jordanian speakers. These mean scores show that the Jordanian were most positively evaluated, followed by the French and finally the Japanese. One possible interpretation for the relatively lower rating of the Japanese accent stems from the vast linguistic differences between English and languages of the Far East inherent in their phonetic, phonological, and structural systems. These results agree with Ryan, 1972 who showed that the European accent was rated higher than other accents and received more positive evaluation than the Far East accents which were rated less positively.

The most remarkable differences between the French and Japanese accents can be found in the two attributes of pleasantness and friendship. It was shown that the French speakers are considerably more pleasant and friendly than the Japanese speakers. This result can be related to the fact that the respondents may be more familiar with French and less familiar with the Japanese language to which they are rarely exposed. From this point, familiarity seems to correlate with friendship. This fact was affirmed by Dalton-Puffer et al., 1997 who implied that participants had a more positive attitude to accents they are familiar with and a more negative attitude to accents they do not identify with because of the insufficient cultural contact between them.

Moreover, the French female speaker education, mentality and attractiveness mean scores were higher than her Japanese counterparts. These results agree with Ben Said, (2006) who concluded that females showed a more positive attitude towards French accent. The relatively high rating of the French female speaker could be attributed to the overrepresentation of females which accounted for $75 \%$ of the whole sample. Overall, the respondents judged the Japanese female speaker as the least refined perhaps on grounds of unfamiliarity with Japanese and Japanese English and this is in line with Ben Said (2006). 
The results in Table 1 showed that the Jordanian speakers' accents (male and female) were the most positively rated and received the highest evaluations in comparison with the other two accents. As Table 1 shows, there were no significant differences between the mean scores of the Jordanian speakers. The overall mean score of the Jordanian female accent was 4.08 , and 4.07 for the Jordanian male accent. Their results are more similar to each other than the mean scores between French female and male speakers and the Japanese female/ male speakers.

The significant differences regarding the attitudes towards the Jordanian accent cannot be directly compared to previous research since no studies have been conducted to investigate attitudes towards the Jordanian foreign accent in comparison with others. Contrary to the results in Table 1, other studies (Johnson and Frederick, 1994, Ben Said, 2006) confirmed less positive attitudes towards the Arab accent and more negative judgments.

As Table 1 shows, the mean scores which suggest the respondents' attitudes towards both Jordanian speakers are the highest; they were considered the friendliest and the most pleasant although the respondents were not familiar with their accent, they could not identify it and most of them do not speak Arabic as a second language or do not have Arabs acquaintances. The results ran counter to the previous studies as Ben Said, (2006) which involved that Arab accents were rated lower than other accents with the lowest evaluations. These results disagree also with Dalton-Puffer et al (1997) who confirmed that the respondents' impression was more positive of the most familiar accent.

In sum, Table 1 shows that the overall means were the highest for the Jordanian female speaker's accent 4.09 and the Jordanian male speaker's 4.07, and were the lowest for the male and female Japanese speakers with mean scores of 2.88 and 2.83 respectively. The French speakers were rated more positively than the Japanese speakers but less positively than the Jordanian speakers on almost all the dimensions as shown in Table 1.

Insert Table 2 here

The positive results towards the Jordanian accent are affirmed by the profession section. More precisely, the respondents considered the Jordanian speakers' professions to be the most prestigious such as teaching or medicine. The Jordanian female speaker for example was described as a teacher by 63 respondents or $57.3 \%$ and as a doctor by 19 or $17.3 \%$ and this is considered a relatively positive evaluation. Again the Jordanian male speaker was rated positively and categorized mostly in the same professions of his female counterpart. Twenty nine participants or $26.4 \%$ categorized him as teacher and the same percentage categorized him as a doctor. However, 21 participants or $19 \%$ of the sample categorized him as a story teller and 12 or $10.9 \%$ categorized him as a salesman

There were also a number of individual comments added by the respondents which viewed the Jordanian female as an architect due to the positive level of pleasantness and acceptance of her accent. In addition, four participants added remarks describing the Jordanian male speaker as a writer which is also considered a remarkable positive attitude towards his accent.

The findings regarding the Jordanian accent ran counter to most previous studies, which described the Arab accents in general as thick, thus triggering discrimination, downgrading and sometimes stereotypes as stated by Ben Said, (2006), and Lippi-Green (1997). No studies have been conducted on the Arabic foreign accent but variations of Arabic accented speech due to the different Arabic dialects such as Egyptian, Jordanian, Lebanese and the Arab Gulf accent. All these variations are not using the same English accent. Ben Said (2006), who conducted his study on immigrants in the US, focused on the Lebanese accent as a sample from the Arab world. In addition to the heavy Arabic accent, the media and animated films characterize the Arabs as wild, brutal and savage groups because of the political situations in the Middle East and the historical conflict between the Islamic and Arabic countries on one hand, and the English speaking countries on the other.

The French female speaker's professions were categorized as follows, nine participants or $8.2 \%$ said she was a doctor, 37 or $33.6 \%$ said she was a teacher, 11 or $10 . \%$ said she was taxi-driver, 12 or $10.9 \%$ said she was a chef and 19 or $17.3 \%$ said she was a saleswoman. The French male speaker's professions were categorized as follows three or $2.7 \%$ said he was a doctor, 40 or $36.4 \%$ said he was a teacher, 14 or $12.8 \%$ said he was a taxi-driver, 20 or $18.2 \%$ said he was a chef and 21 or $19.1 \%$ said he was a salesman. A relatively low percentage of approximately $14.5 \%$ of the sample categorized the French speakers to be in the chef and cuisine professions and this is contrary to Trowel 2007, who claimed that the French accented English was related to a chef profession because of media and animated films which had chosen the French accent for the chef character, but as shown in Table 2, more respondents chose the teacher and salesman as professions for the French speakers

The Japanese speakers' professions were categorized as follows The female speaker, for example was described as a doctor by five or $4.5 \%$ and as a teacher by 22 respondents or $20 \%$ and as a taxi-driver by 15 or $13.6 \%$ and as a chef by 21 or $19 \%$ and as a saleswoman by 15 or $13.6 \%$. The male speaker's professions were categorized as follows 13 
or $11.8 \%$ said he was a doctor, 19 or $17.2 \%$ said he was a teacher, 36 or $32.7 \%$ said he was a taxi-driver, 15 or $13.6 \%$ said he was a chef and 13 or $11.8 \%$ said he was a salesman. Table 2 clearly shows that $63.6 \%$ of the sample categorized the Jordanian speakers in prestigious professions, namely teaching and medicine, whereas only $40.4 \%$ and $26.8 \%$ categorized the French and Japanese speakers in these professions respectively. Prestige is a relative matter which shows the standing of a person or an object in relation to other people or things, but when used with respect to language, it refers to a variety which society associates with education and high society status.

\subsection{Nationality}

When respondents were asked about the nationality of each speaker, their responses showed relatively high patterns of recognition of the speakers under investigation as $47.7 \%$ of them said that the French speakers came from Europe, in comparison with $41.8 \%$ who said that the Japanese speakers came from the Far East and $23.2 \%$ who said that the Jordanian speakers came from the Middle East as shown in Table 3. The other nationality categorizations of the French speakers were as follows: $20.4 \%$ said that they came from the Middle East, $6.8 \%$ said they came from the Far East, $5.9 \%$ said they came from India and only 5.4\% said they came from Russia. The other nationality categorizations of the Japanese speakers were as follows: $17.3 \%$ said that they came from Africa, $16.8 \%$ said they came from the Middle East and 6.4\% said they came either from Europe or India. The other nationality categorizations of the Jordanian speakers were as follows: $20.4 \%$ said that they came from Europe, $18.2 \%$ said they came from India, 5.9\% said they came from the Far East and 6.4.9\% said they came from Anglophone countries. It is noteworthy to mention here that only Jordanian speakers were categorized as coming from an Anglophone country which may indicate that their accent was accurate, fluent and native-like.

Insert Table 3 here

As stated above $18.2 \%$ of the respondents stated that the Jordanian speakers came from India. One interpretation for this lies in the fact that the Indian speakers of English in North America are more fluent and their rate of speech is faster, so perhaps because of the fluency of the Jordanian speakers, the respondents perceived them as Indians and their accent as an Indian accent

Recognition of the Jordanian speakers as of Middle Eastern nationality could be directly related to the covering letter of the questionnaire in which the Middle East University was mentioned, so the respondents might have got a clue that all the speakers were from the Middle East..

\subsection{Intelligibility}

\section{Insert Table 4 here}

With regard to the first question of section three which elicited data as to accent clarity or vagueness, the highest mean scores were for the Jordanian speakers 4.4 followed by the French 3.2, and finally the Japanese speakers 2.5. This clearly shows that the Jordanian accent was the clearest to understand followed by the French and finally the Japanese accent. As to accent intelligibility, the mean scores were as follows 4.4 for the Jordanian speakers, 3.1 for the French speakers and 2.45 for the Japanese speakers. This clearly shows that the Jordanian accent was the easiest to understand and the Japanese accent the most difficult to understand. With regard to the accent and the extent to which it helped in understanding the text, the mean scores were as follows: 3.95 for the Jordanian speakers, 2.75 for the French speakers and finally 2.3 for the Japanese speakers. Again, this shows that the Jordanian English accent helped respondents most in comprehending and understanding the spoken text, whereas the Japanese accent helped least in understanding it. As to speakers' intonation and the extent to which it helped participants understand the recorded texts, the mean scores were 4.1 for the Jordanian speakers' accent, 2.9 for the French speakers' accent and 2.35 for the Japanese. This again indicates that the intonation patterns of the Jordanian speakers approximated those of the native speakers or were native -like; on the contrary, the Japanese intonation patterns sounded strange and unexpected for the native speakers of English. So the data in Table 4 affirm that the intelligibility and receptivity of the Jordanian English accent which ranked first, the French accent ranked second and the Japanese which ranked English last.

Table 4 shows the highest evaluation of the Jordanian accent in comparison with the other two accents. Not only does the Jordanian accent have the highest positive attitudes, but also it is the clearest in comparison with the French and Japanese accents. The Jordanian speakers' (male and female) accent was rated as the most understandable as shown by the mean scores.

Previous studies showed that there are linguistic differences between English and Japanese (Raslan \& Hansen 1996). For example, in Japanese, there are no diphthongs. So, in case two vowels appear in the same word consecutively, Japanese speakers cannot pronounce the word correctly (i.e. the word eat is mostly pronounced as $i t$ ). Moreover, the Japanese speakers substitute the consonant $/ 1 /$ with $/ \mathrm{r} /$ because this sound does not exist in the Japanese language. 
These sound differences and others may explain the lack of correct pronunciation and articulation on the part of Japanese speakers

Table 4 shows the highest evaluation of the Jordanian accent in comparison with the other two accents. Not only does the Jordanian accent have the highest positive attitudes, but also it is the clearest in comparison with the French and Japanese accents. The Jordanian accent was rated as most understandable one for both male and female Jordanian speakers as shown by their mean scores.

The majority of the listeners could understand (76\%-100\%) of the texts recorded and delivered by the Jordanian speakers. Moreover, pronunciation accuracy and the speakers' fluency were rated positively by the respondents who rated the Jordanian speakers (male and female) accent as the most understandable accent between the three accents.

The respondents' comprehension level of the Jordanian accent was the highest of all percentages of the groups of the study. Speakers' fluency percentages are higher than the other four accents. These findings are in contrast to Ben Said, (2006) who rated Jordanian accent as fluent with clear intonation and with accurate pronunciation. Raslan \& Hansen (1996) also revealed that the speakers of English were not intelligible because of the linguistics differences inherent in the phonological system between the two languages. They explained that in pronouncing words such as (dad, cat, add, and), the Arab substitute the /aa/ for the /ae/ phoneme consistently. They added that whose native language is Arabic in pronouncing words such as there; those substitute the (th) with /z/ and substitute the (th) in three by $/ s /$ sound. These findings did not counterpart the Jordanian accent, but they might be interpreted on the Lebanese or Syrian English accented speech.

With respect to (Flege 1987) who indicated that foreign accent was repeatedly associated with low intelligibility and negative personal evaluations of nonnative speakers, this fact is not confirmed by the Jordanian accent which is presented as an intelligible accent. In reference to Derwing \& Munro (1997) and Munro \& Derwing (1995), accentedness, comprehensibility and intelligibility are related. Theoretically, a light accent is easier to understand than a strong one. Derwing \& Munro (1997) stated that weak accent did not always correlate with easier comprehension and intelligibility, nor did a heavy accent always delay comprehension. In the present study, the Japanese accent hindered understanding of the text while the Jordanian accent guaranteed an easier understanding of the text.

The previous studies used native speakers of English to teach English at school or at universities because they are more understandable, affirm that nonnative speakers should follow accent programs to improve their way of speaking so they can be more respectable Derwing (2003).

However, the results of the present study revealed that the Jordanian accent was a highly valued one, although their speakers did not follow any language program or meet any native English speakers!

With regard to the accuracy of the French, Japanese and Jordanian speakers' accents, $65.5 \%$ of the respondents said the French speakers accent was either " very accurate" or " accurate", and 35\% said that the Japanese accent was either "very accurate" or "accurate" and finally, 96\% said the Jordanian accent was either "very accurate" o $r$ 'accurate"

In addition, $34.5 \%$ of the respondents said that the French accent was either "somewhat accurate" or "inaccurate" and $66 \%$ said that the Japanese accent was either "somewhat accurate" or "inaccurate" and finally $4 \%$ said that the Jordanian accent was either ' somewhat accurate" or "inaccurate" as shown in Table 5 below.

Insert Table 5 here

In addition, $65.5 \%$ of the respondents said the French speakers accent was either "accurate" or "very accurate", and $34 \%$ said that the Japanese accent was either "accurate" or "very accurate" and finally, $96 \%$ said the Jordanian accent was either "accurate" o $r$ "very accurate"

With regard to the accent fluency of the French, Japanese and Jordanian speakers, $30.5 \%$ of the participants said that the French speakers accent was "very fluent", $36 \%$ said that they were "fluent' and $26.5 \%$ said they were "somewhat fluent". The participants characterization of the Japanese speakers were as follows: $23.5 \%$ said they were 'very fluent', $34 \%$ said they were 'fluent', and $29.5 \%$ said they were 'somewhat fluent'. The Jordanian speakers' fluency was characterized as follows: $80 \%$ said that they were 'very fluent', $15 \%$ said they were 'fluent' and $4 \%$ said they were "somewhat fluent'. The data showed that only $30.5 \%$ of the French speakers and $23.5 \%$ of the Japanese and $80 \%$ of the Jordanians were "very fluent". This indicates of course the fluency of the Jordanian accent and the positive attitude towards it as shown in Table 6.

Insert Table 6 here 


\section{Summary and Conclusion}

The findings showed that there was a quantitative and a qualitative difference between French, Japanese and Jordanian English. Jordanian English was rated more positively on many dimensions such as clarity, fluency and accuracy than French English which in turn was rated more positively than Japanese English. In line with this, native speakers of English viewed Jordanian English more favorably than French and Japanese English. The latter perceived as the least favorable of all accents under investigation. These ratings apply of courses to accented English which is recorded by the individual speakers of English and may not hold true of accented speech of all French, Japanese and Jordanian speakers.

It is claimed that native and non-native speakers of English hold biases with regard to foreign speech, and this is perhaps due to the low intelligibility and partial or total incomprehensibility of accented speech by native speakers of English. Such biases and prejudices may even apply to native speakers with dialect different from the standard language thus triggering prejudices and discrimination.

It is thus not unusual for some foreign speakers to enroll in accent reduction courses to mitigate or eliminate their accent to be more intelligible and sound more like native speakers.

The researchers here believe that more emphasis should be given to the intelligibility and fluency of foreign speech than to native or native-like accent because neurolinguistic research has unequivocally confirmed that native accent can not be acquired after puberty age. In addition, what matters is the intelligibility of foreign speech and native or non- native speakers' comprehensibility of it because after all the goal of learning English is the ability to communicate, interact and use the language and not acquire native accent. Of the two, perfect pronunciation or communication, the latter must always be given precedence.

\section{References}

Arslan. L.,\& Hansen, J (1996). Language accent classification in American English. Speech communication, vol. 18, 353-367. http://dx.doi.org/10.1016/0167-6393(96)00024-6

Asher, J., \& Garcia, R. (1969). The optimal age to learn a second language. The Modern Language Journal, vol. 53, 334-341. http://dx.doi.org/10.2307/323026

Becker, P. (1995). The etiology of foreign accent: Towards a phonological component of identity. Unpublished master's thesis. Southern Illinois University, Carbondale.

Ben Said, S. (2006). Attitudes towards accented speech: comparative study of native and non native speakers of American English. Unpublished thesis. Southern Illinois University Carbondale.

César lee B. (1999). Quantification of accented pronunciation by American English speakers in French as a foreign language setting. Unpublished doctoral dissertation. University of Florida, Florida.

Dalton, Puffer, C., \& Kaltenboeck, F. Smit. (1997). Learner attitudes and L2 pronunciation in Austria. World Englishes, 16 (1), 115-128

Derwing, T. (2003). What do ESL Students say about their accents? The Canadian Modern Language Review, Vol. 59, 547-566. http://dx.doi.org/10.3138/cmlr.59.4.547

Felps, D. Bortfeld, \& H. Osuna, R. (2009). Foreign accent conversion in computer assisted pronunciation training. Speech Communication, 51, 920-932

Flege, J. (1984). The detection of French accent by American listeners. Journal of acoustical society of America, 76, 70-79. http://dx.doi.org/10.1121/1.391256

Flege, J. Birdsong, D. Bialystok, E. Mack, M. Sung, H., \& Tsukada, K. (1988). Factors affecting degree of perceived foreign accent in English sentences. Acoustical Society of America, 84, 70-79

Flege, J., \& Fletcher, K. (1992). Talker and listener effects on degree of perceived foreign accent. Acoustical Society of America, vol. 91, 370-389

Flege, J. (1995). Second language speech learning theory findings and problems. Speech perception and linguistic experience: issue in cross-language research, 232-277

Flege, J. Munro, M., \& Mackay, I. (1995). Factors affecting strength of perceived foreign accent in a second language. Acoustical Society of America, 97, 3125-3134

Flege, J. (2006). Degree of foreign accent in English sentences produces by Korean children and adults. Journal of Phonetics, 34, 153-175 
Gill, M. (1994). Accent and stereotypes: Their effect on perceptions of teacher and lecture comprehension. Journal of Applied Communication Research, 22, 348-361

Johnson, R., \& Frederick, L. (1994). Native speakers' perceptions of nonnative speakers. Paper presented at the annual meeting of the Teachers of English to speakers of other languages. Baltimore, Maryland.

Khalil, A. (1996). A contrastive language acquisition. Al-Isra press, Jerusalem.

Lippi-Green, R. (1997). English with an accent: language, ideology and discrimination in the United States. London, Routledge.

Munro, M., \& Derwing, T. (1995b). Processing time, accent and comprehensibility in the perception of native and foreign-accented speech. Language and Speech, 38, 289-306

Munro, M. (1998). The effects of noise on the intelligibility of foreign-accented speech. Studies in Second Language Acquisition, 20, 139- 154

Piske, T., Mackay I., \& Flege, J. (2001). Factors affecting strength of perceived foreign accent in a second language. Journal of Phonetics, 29, 191-215. http://dx.doi.org/10.1006/jpho.2001.0134

Ryan, Michael. (1972). Stereotypes, credibility, and foreign accented English speech. Oxford: Oxford University Press.

Suter, R. (1976). Predictors of pronunciation accuracy in second language learning. Language Learning, 26, 233-25. http://dx.doi.org/10.1111/j.1467-1770.1976.tb00275.x

Thomas, L. (1999). language, society and power: an introduction. London, Routledge.

Trowel M. (2007). A test of the effects of linguistic stereotypes in children's animated film: A language attitude study. University of north Texas.

Table 1. Mean scores of respondents attitudes' towards different types of English

\begin{tabular}{|l|l|l|l|l|l|l|}
\hline & French male & $\begin{array}{l}\text { French } \\
\text { female }\end{array}$ & $\begin{array}{l}\text { Japanese } \\
\text { male }\end{array}$ & $\begin{array}{l}\text { Japanese } \\
\text { female }\end{array}$ & $\begin{array}{l}\text { Jordanian } \\
\text { male }\end{array}$ & $\begin{array}{l}\text { Jordanian } \\
\text { female }\end{array}$ \\
\hline pleasant & 3.3 & 3.6 & 2.6 & 2.7 & 4.2 & 4.0 \\
\hline educated & 3.5 & 3.7 & 2.9 & 2.7 & 4.2 & 4.3 \\
\hline confident & 3.0 & 3.7 & 3.0 & 2.6 & 4.4 & 4.3 \\
\hline warm & 3.3 & 3.4 & 3.0 & 2.9 & 4.1 & 4.0 \\
\hline class & 3.3 & 3.3 & 2.8 & 2.7 & 3.8 & 3.7 \\
\hline rich & 3.2 & 3.2 & 2.8 & 2.7 & 3.8 & 3.6 \\
\hline friendly & 3.8 & 3.4 & 3.0 & 3.2 & 4.1 & 4.1 \\
\hline hard working & 3.4 & 3.2 & 3.1 & 3.1 & 4.0 & 4.0 \\
\hline smart & 3.5 & 3.6 & 3.0 & 3.0 & 4.3 & 4.2 \\
\hline attractive & 3.1 & 3.4 & 2.6 & 2.7 & 3.8 & 3.7 \\
\hline Overall means & 3.34 & 3.45 & 2.88 & 2.83 & 4.07 & 4.08 \\
\hline
\end{tabular}


Table 2. Respondents' categorization of the French, Japanese and Jordanian speakers' professions

\begin{tabular}{|l|l|l|l|l|l|l|}
\hline \multicolumn{1}{|c|}{ Profession } & $\begin{array}{l}\text { French } \\
\text { male }\end{array}$ & $\begin{array}{l}\text { French } \\
\text { female }\end{array}$ & $\begin{array}{l}\text { Japanese } \\
\text { male }\end{array}$ & $\begin{array}{l}\text { Japanese } \\
\text { female }\end{array}$ & $\begin{array}{l}\text { Jordanian } \\
\text { male }\end{array}$ & $\begin{array}{l}\text { Jordanian } \\
\text { female }\end{array}$ \\
\hline Doctor & 3 & 9 & 13 & 5 & 29 & 19 \\
\hline Teacher & 40 & 37 & 19 & 22 & 29 & 63 \\
\hline taxi driver & 14 & 12 & 36 & 15 & 1 & 3 \\
\hline Chef & 20 & 12 & 15 & 21 & 2 & 3 \\
\hline Salesman & 21 & 19 & 13 & 15 & 21 & 3 \\
\hline story teller & 1 & 2 & 1 & 1 & 12 & 2 \\
\hline Student & 4 & 4 & 1 & 1 & ----- & 2 \\
\hline office work & 1 & 1 & ----- & ----- & ---- & 1 \\
\hline Architect & 1 & 3 & ----- & ----- & ----- & 3 \\
\hline writer & ----- & 1 & ---- & ---- & 4 & ----- \\
\hline house keeping & ----- & 1 & 4 & 10 & & \\
\hline & & & & & & \\
\hline Unemployed & & & & 6 & & \\
\hline Other & 8 & 9 & 8 & 14 & 12 & 11 \\
\hline
\end{tabular}

Table 3. Respondents' characterization of the speakers' national background

\begin{tabular}{|l|l|l|l|l|l|l|}
\hline & $\begin{array}{l}\text { French } \\
\text { male }\end{array}$ & $\begin{array}{l}\text { French } \\
\text { female }\end{array}$ & $\begin{array}{l}\text { Japanese } \\
\text { male }\end{array}$ & $\begin{array}{l}\text { Japanese } \\
\text { female }\end{array}$ & $\begin{array}{l}\text { Jordanian } \\
\text { female }\end{array}$ & $\begin{array}{l}\text { Jordanian } \\
\text { male }\end{array}$ \\
\hline Middle East & 28 & 17 & 18 & 19 & 31 & 20 \\
\hline Europe & 56 & 49 & 9 & 5 & 22 & 23 \\
\hline Far East & 2 & 13 & 33 & 59 & 4 & 9 \\
\hline Africa & 5 & 4 & 27 & 11 & 4 & 1 \\
\hline India & 8 & 5 & 8 & 6 & 19 & 21 \\
\hline Russia & 3 & 9 & 3 & ---- & 3 & 6 \\
\hline Anglophone & ---- & ---- & ---- & ---- & 5 & 9 \\
\hline other & 13 & 13 & 10 & & 23 & 27 \\
\hline
\end{tabular}

Table 4. Mean scores of speakers' intelligibility and accent clarity

\begin{tabular}{|l|l|l|l|}
\hline & $\begin{array}{l}\text { French } \\
\text { speakers }\end{array}$ & Japanese speakers & $\begin{array}{l}\text { Jordanian } \\
\text { speakers }\end{array}$ \\
\hline Clearness & 3.2 & 2.5 & 4.4 \\
\hline Easiness & 3.1 & 2.45 & 4.4 \\
\hline Accent helps in understanding & 2.75 & 2.3 & 3.95 \\
\hline $\begin{array}{l}\text { Intonation helps in } \\
\text { understanding the text }\end{array}$ & 2.9 & 2.35 & 4.1 \\
\hline
\end{tabular}


Table 5. Respondents' perception of the accuracy of French, Japanese and Jordanian speakers

\begin{tabular}{|l|l|l|l|l|l|l|}
\hline \multirow{2}{*}{} & \multicolumn{2}{|l|}{ French Speakers } & \multicolumn{2}{l|}{ Japanese Speakers } & \multicolumn{2}{l|}{ Jordan Speakers } \\
\cline { 2 - 7 } & Male & Fem. & Male & Fem. & Male & Fem \\
\hline very accurate & $19 \%$ & $30 \%$ & $10 \%$ & $5 \%$ & $70 \%$ & $70 \%$ \\
\hline accurate & $44 \%$ & $38 \%$ & $28 \%$ & $25 \%$ & $28 \%$ & $24 \%$ \\
\hline somewhat accurate & $26 \%$ & $32 \%$ & $43 \%$ & $36 \%$ & $1 \%$ & $5 \%$ \\
\hline Inaccurate & $11 \%$ & $0 \%$ & $19 \%$ & $34 \%$ & $1 \%$ & $1 \%$ \\
\hline
\end{tabular}

Table 6. Respondents' perception of the fluency of French, Japanese and Jordanian speakers

\begin{tabular}{|l|l|l|l|l|l|l|}
\hline & \multicolumn{3}{|l|}{ French Speakers } & \multicolumn{2}{l|}{ Japanese Speakers } & \multicolumn{2}{l|}{ Jordan Speakers } \\
\cline { 2 - 7 } & Male & Fem. & Male & Fem. & Male & Fem \\
\hline very fluent & $23 \%$ & $38 \%$ & $38 \%$ & $9 \%$ & $82 \%$ & $79 \%$ \\
\hline fluent & $41 \%$ & $31 \%$ & $31 \%$ & $37 \%$ & $15 \%$ & $15 \%$ \\
\hline Somewhat fluent & $23 \%$ & $30 \%$ & $30 \%$ & $29 \%$ & $3 \%$ & $5 \%$ \\
\hline not fluent & $13 \%$ & $1 \%$ & $1 \%$ & $25 \%$ & $0 \%$ & $1 \%$ \\
\hline
\end{tabular}

